\title{
A broadened criterion to assess safety factor of industrial products design for ecological balancing
}

\author{
Mohamed Reda Ramadan Gomaa ${ }^{1}$, M. A. S. Mohamed ${ }^{2}$ \\ ${ }^{1}$ Industrial Engineering Department, Alexandria Higher Institute for Engineering \& Technology, Alexandria, Egypt \\ ${ }^{2}$ Arab Academy for Sciences and Technology, Cairo, Egypt \\ Email address: \\ mredarg@yahoo.com (Mohamed Reda Ramadan Gomaa), Logarithm48@hotmail.com (M. A. S. Mohamed)
}

\section{To cite this article:}

Mohamed Reda Ramadan Gomaa, M. A. S. Mohamed. A Broadened Criterion to Assess Safety Factor of Industrial Products Design for Ecological Balancing. International Journal of Science, Technology and Society. Vol. 3, No. 1, 2015, pp. 1-8.

doi: $10.11648 /$ j.ijsts.20150301.11

\begin{abstract}
The problem of selecting a suitable safety factor for industrial products, and especially for a design proposal is reviewed. Products are mainly introduced to provide a certain profit or turnover in terms of resources enhancement. However, any proposed product will somehow drain natural resources whether it operates properly or erroneously. A comprehensive definition of products safety is put forth to face the numerous requirements placed on sophisticated products. Product safety is then assessed based on its consequential loss in resources. The suggested definition is checked using the three commonly applied methods of product safety estimation; namely the product quality, the FMEA technique, and the Markov formulation. It is found that product safety in the broadened presented sense as a compromised viewpoint is often sought in order to reach a balance between their useful and harmful aspects with regards to all members of the ecological system. Moreover, product safety does embrace the gain/loss statistical data of product introductory versions and represents a trade-off function of its profits (resources renovation) and its losses (resources drain). In addition, the comprehensive resource-loss trend helps product designers meet a wide range of customer requirements and operational regulations as perspective environmental closed system (ECS).
\end{abstract}

Keywords: Safety Factor, Manufactured Products, Environmental Closed System (ECS), Statistical Process Control (SPC), Failure Modes and Effect Analysis (FMEA), and Markov Chains

\section{Background}

In the past era, a product design was proposed so as to satisfy a number of user typical demands and expected requirements, subject to manufacturing capabilities and technical constraints. Skilled designer used to follow systematic steps, which are always bound to a satisfactory prototype. The commonly used safety factor in design is a quick tool to check the proposed draft of a component compared to the allowable yield or strength [1]. This criterion is mainly implemented to avoid failure, to prevent damages and to reduce losses in properties and lives [2]. The designer undergoes a technical state of compromising. High safety factor or higher user safety needs huge expenditures. Low safety factor or low safety increases the risk and its huge consequent losses [3]. When selecting the product raw material, another state of compromise between a rare high-cost material and an available low-strength material. Manufacturing accuracy also is another example of compromise between extra and rough finishing [4].

Nevertheless the today customer has exorbitant and challenging demands, and the today shop floors are equipped with highly sophisticated machines such as robots and CNC machines [5]. As for technical aids, computer-based packages and advanced testing devices outreached typical designer proposals and thoughts. In addition, the health and safety regulations are so increasingly restrains environmental violations that the traditional safety factor with its conventional sense is no longer satisfactory [6]. It is true that traditional safety factor proved successful for typical and simple design proposals. Nevertheless, this approach shows numerous and essential conservations when handling intricate tasks [7]. In this study we extend the concept of safety factor to include broad and various aspects of safety. Based on this context, safety embraces the protection of the user, his assets and his resources. High safety means full and perfect protection of assets, guarding the resources from losses, preventing or minimizing the losses. 


\section{The Gain/Drain of Resources}

A comprehensive environmental system consists of six entities, being man, animal, plants, air, water, and land. This system is self-balanced long time ago. Balance means that these six entities coexist with a hidden formula of mutual agreement and interactions so that in the end of any conflict they all must remain in the system in order that any one else remains. Compulsory interactions result in useful and harmful parallel effects. In other words, interacting entities may gain, loose, or break even depending on the objective and needs for interactions. Based on Markov theory, since the number of entities is constant and the circumstances are unchanged, they should reach an equilibrium state. Recorded history tells us nothing unusual and advocates this theory, though some minor negligible exceptions may be mentioned such as floods, volcanoes, and wars. As late as the eighteenth century, man felt unsatisfied with the typical norms of living, he then started to introduce two new entities, being the modern city style and the industrial plants/ manufactured products. The main purpose of modern cities was to improve the living standards, such as settlement near rich natural resources, road pavement, animal dispelling, building reinforced concrete, waterway shrinkage, and concentrated wastes. We should recall that each activity has both beneficial and detrimental aspects. The beneficiary is always and mainly the man, the hurt entity may be one of the other five entities or even the man himself. Irreversibility is a common feature for any of such activities. For instance, a road pavement means a permanent modification of the original natural structure of the land with a minor likelihood of its fertility recovery. Industrial plants and their manufactured products are introduced for the man prosperity. Cars, transportation means, textiles, and fuel refineries have well known useful aspects mainly for man. They, themselves, have also harmful aspects for the man and other entities as well. For instance, any manufactured product has wastes, which hurt air, water, land, animal, plants, and man. It is fair to expect that the man intelligence to introduce a complex product is not less than his brainpower to get rid of its wastes.

Let us wonder whether today s man can accept to move backward and live as he was two hundreds years ago. The answer is expectedly no since new generations used to move forwards and to instate upgraded civilizations. This leads to a conclusion that we should live with the two added entities as established facts. However, since these two entities are manmade, their useful and harmful effects should be compromised and controlled.

\subsection{Characteristic Features of the Two New Entities Compared to the Six Original Entities}

a) They are manmade

Man knows how he has designed them, constructed them, developed them, and how to operate them. Since they are manmade, they inevitably and knowingly should include some type of defects. However, man is still capable to know where their defects might be, and when they have to be maintained, repaired, controlled, and altogether replaced.

b) They are resource consuming

Depending on the sophistication of the introduced entities, some type of resources should be spent. This aspect reflects the economic feature in the entity. Accordingly the creation involves an optimization technique.

c) They continuously change towards advanced versions every minute. Uninterrupted improvement incorporates their development, expansion, multiplication, complexity, and sophistication. For instance, both industrial plants and products grow in number and technology.

d) They have an unlimited and open range of variation within any arbitrary type. On the large scale, manufactured products such as cars are numerous in purpose and in diversity.

\subsection{Defects in a Product}

Defects triggers are classified as

a) Intrinsic, skill of the design crew and techniques

b) Intrinsic, manufacturing techniques (modest technology, inferior processes, machines, inspection, measurements, testing)

c) Induced, user, overload, misuse, negligence, ignorance, disregarded maintenance, and behavioral.

Due to aging (rust) and operation (wear), defects grow up and alter the product performance. This results in new symptoms, which may gradually or suddenly appear. As a general fact, a defect growth leads to certain losses. Losses take different forms such as money, properties, lives, injuries, deformation, inability, malfunctioning, shorter service life, breakdown, collapse, failure, inefficiency, and handicapped.

\section{The Quality Approach}

Absolute quality of a system expresses its freedom from defects. Since defects growth are the main source of consequent resource losses, absolute safety of a system is theoretically reached whenever its freedom of defects is ensured. Thus a safe product means the absence of defects leading to losses, and unsafe product means the presence of defects leading to losses.

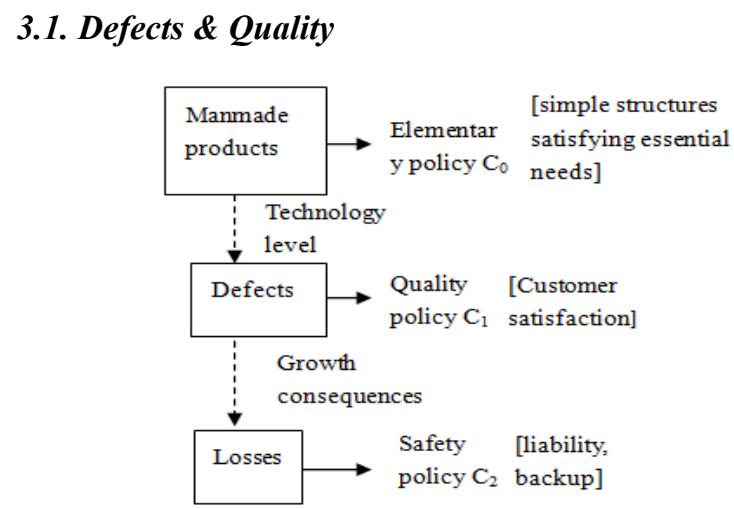

Figure 1. Grades of concern as manmade products become complicated, sophisticated, and multi. 
The normal or abnormal implementation of a product leads to a defect slow or fast growing up. Defect growth results in

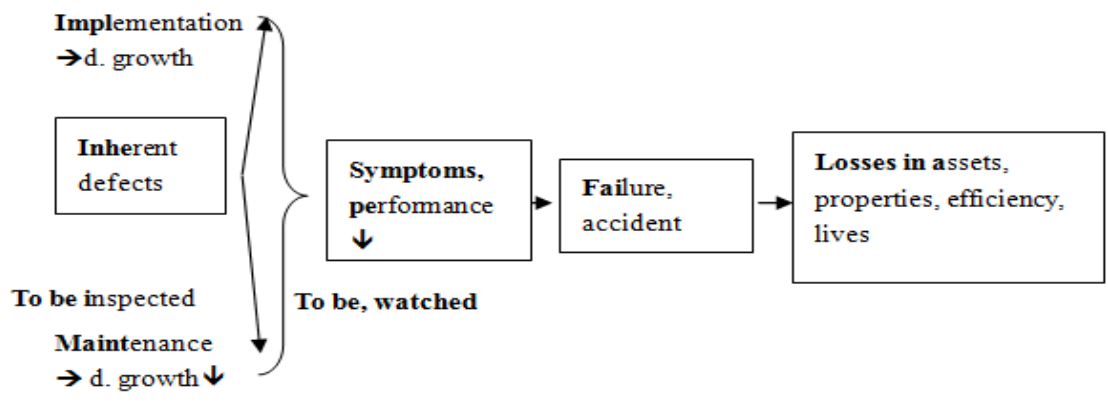

Figure 2. How to link product purpose defects to safety.

Common meaning of safety refers to loss in man life, body deformation, drop of physical fitness, slow or fast illness, health disturbances, and diseases. Wide meaning of safety incorporates significant loss incurred by assets, whether for man or for other natural resources.

For the product safety assessment, literature [8] show that the checked safety $\mathrm{S}$ is evaluated nowadays by two rates;

a) Accident is a consequence of a defect growth.

Accident frequency rate: accident density

Frequency rate $=$ No of accidents $/$ No of working hours

b) An accident seriousness/ severity is assessed in terms of its resulting losses (damaged properties/ injured or inoperative manpower / broken down/ incapable capacities).

Severity rate $=$ No of wasted work days/ No of working hours

\subsection{The Safety as an Ingredient of a Perfect Quality}

The ISO 9000 code shows a requirement list to score the product quality. The code no 19 is named product safety and liability with no elements yet marked. This simply means that safety is one of the elements that product quality encompasses. In other words, a product should involve an acceptable safety feature in order to issue its quality perfection. The absence of the code elements reflects a vacant area of widely debated arguments as for

1. There are no worldwide safety regulations to abide by.

2. There are no standard measures to assess a product safety

3. There are no conversion equivalences to compare different products.

4. There are no guidelines for cost compromising towards an accepted level of safety.

5. There is no a unified methodology for safety control.

6 . There are no dependable or tested recommendations to enhance and upgrade a low-safety product.

\subsection{The Simple-Scale Model}

The positive aspect

Man introduces a new type of product. This product has a kind of benefit for man. Man keeps improving and maximizes the product efficiency. inadequate/ altered performance, failure, harmful consequences, and losses, see "Figs. 1and 2".

\section{The negative aspect}

In the manufacturing (before-birth) stage, great loss in terms of effort, money, cost, harm, is spent to reduce defects number and severity. This indicates and provokes a direct dependence of the form Preventive cost $\alpha$ safety.

Assuming a linear proportionality, we get

$$
\mathrm{C}_{1} \propto \mathrm{S}
$$

The market end product should finally include some type of inevitable, inherent, or intrinsic defects. In the implementation (after-birth) stage, inherent defects grow up and efficiency drops.

Manufacturer liability implies to afford an after sale service cost (maintenance, repair, and replacement). In addition, insurance compensations have to cover losses in lives and damages in properties. This indicates an inverse dependence as

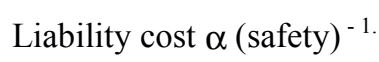

Assuming a simple dependence, we get

$$
\mathrm{C}_{2} \propto \mathrm{S}^{-1}
$$

At any arbitrary defect level, or equivalently a safety level, the total cost $\mathrm{C}$ is then

$$
\begin{aligned}
\mathrm{C} & =\mathrm{C}_{0}+\mathrm{C}_{1}+\mathrm{C}_{2} \\
\mathrm{C}(\mathrm{S}) & =\mathrm{C}_{0}+\mathrm{a} \mathrm{S}+\mathrm{b} \mathrm{S}^{-1}
\end{aligned}
$$

Where $\mathrm{C}_{0}$ is the default cost to create or introduce the new product to the markets. The plot of this function is shown in "Fig. 3". It is noticed that both extremities of high and poor safety lead to unaffordable costs or harms. To optimize the total cost, we differentiate w.r.t. S, then equate to zero, i.e.

$$
\begin{aligned}
{[\mathrm{d} / \mathrm{dS}] \mathrm{C}(\mathrm{S}) } & =\mathrm{a}-\mathrm{b} \mathrm{S}^{-2}=0 \\
\mathrm{~S}^{-2} & =\mathrm{a} / \mathrm{b} \\
\mathrm{S}^{2} & =\mathrm{b} / \mathrm{a}
\end{aligned}
$$

The recommended safety level, involving accepted defects, is given by

$$
\$=\{\mathrm{b} / \mathrm{a}\}^{0.5}
$$


Substituting in the cost function, we get the minimum cost as

$$
\begin{aligned}
& \mathrm{C}_{\min }=\mathrm{C}(\$) \\
& =\mathrm{C}_{0}+\mathrm{a} \$+\mathrm{b} \$^{-1} \\
& =\mathrm{C}_{0}+\mathrm{a}\{\mathrm{b} / \mathrm{a}\}^{0.5}+\mathrm{b}\{\mathrm{b} / \mathrm{a}\}^{-0.5} \\
& =\mathrm{C}_{0}+\{\mathrm{b} \mathrm{a}\}^{0.5}+\{\mathrm{b} \mathrm{a}\}^{0.5} \\
& =\mathrm{C}_{0}+2\{\mathrm{~b} \mathrm{a}\}^{0.5}
\end{aligned}
$$

positive for any arbitrary $\mathrm{S}$, thereby the loss function definitely undergoes a minimum. These results are plotted The second derivative given by

$$
\left[\mathrm{d}^{2} / \mathrm{dS}^{2}\right] \mathrm{C}(\mathrm{S})=2 \mathrm{~b} \mathrm{~S}^{-3}
$$

is always in "Fig. 3" for the data published by car manufacturer strategic alliance of Chrysler, GM, and Ford $[8]$.

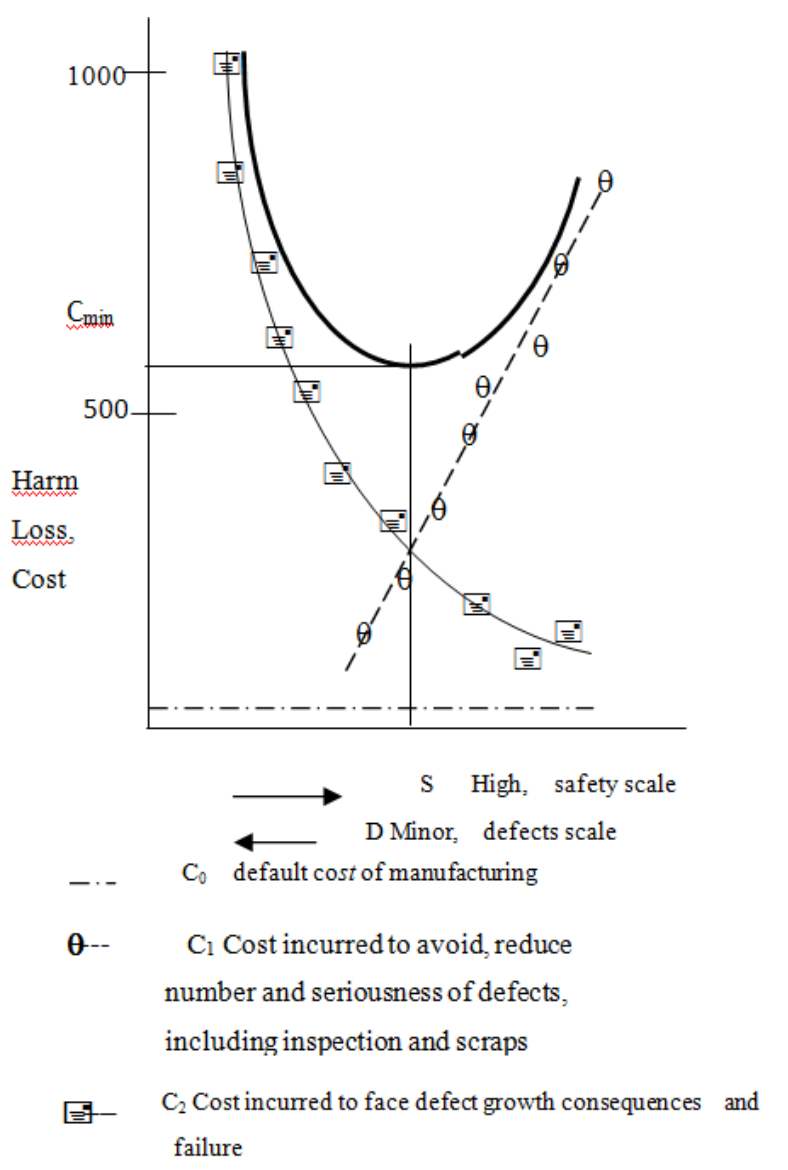

Figure 3. Optimization technique to minimize negative effects of useful products.

\section{The FMEA Technique}

The FMEA, Failure Modes and Effect Analysis, relies on the evaluation of what is so called Risk Priority Number [9]. The number non-linearly ranges from 1 to 1000 , the smaller the number the better the product quality. The RPN number itself is the product of three factors, each being an integer from 1 to 10 . We should expect similar values of RPN due to various combinations of the three factors. In other words, we have a total of 1000 possible RPN, some of which have similar values. The first factor is named Detection, which reflects the designer and inspection role. It expresses the degree of clearness of technical defects to be caught by the inspection device. Designer imprudence, ignorance, rough-accuracy testers are given large values, e.g. 9 or 10 . The second factor is named Occurrence, which expresses the deficiency of manufacturer s capacity or his inability in terms of the defected fraction in a product lot. When the lot is dominated by defected items, the Occurrence takes on high values, e.g. 9 or 10 . The third factor is called Severity, which expresses the user ability to observe the product defects and his subsequent loss. It expresses the degree of clearness of defects to be caught by the user. When the defect is so clear for the ordinary user to readily catch, the defect detrimental effect is great and the severity factor becomes high, e.g. 9 or 10 .

This approach is used for progressive comparison of two developmental versions of one design proposal, or to compromise between two design versions.

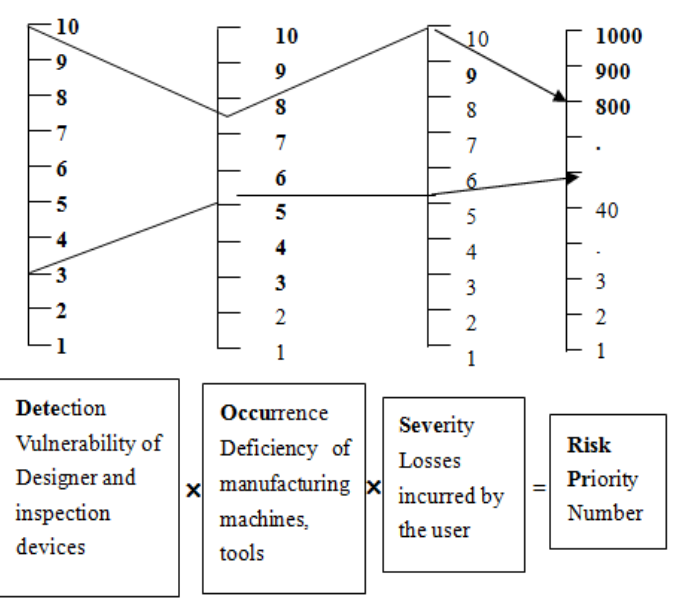

Figure 4-a. Histogram representation of the FMEA scale $[D, O, S] \rightarrow R P N$, comparison of two design proposal versions $[10,8,10] \rightarrow 800 \&[2,5,4]$ $\rightarrow 40$.

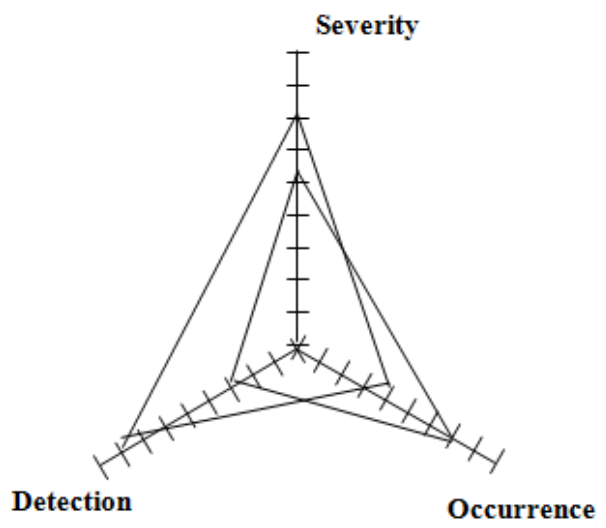

Figure 4-b. Polar representation of the FMEA scale [D, O,S] $\rightarrow R P N$, comparison of two design proposal versions $[9,5,8] \rightarrow 360 \&[4,8,6]$ $\rightarrow 192$. 


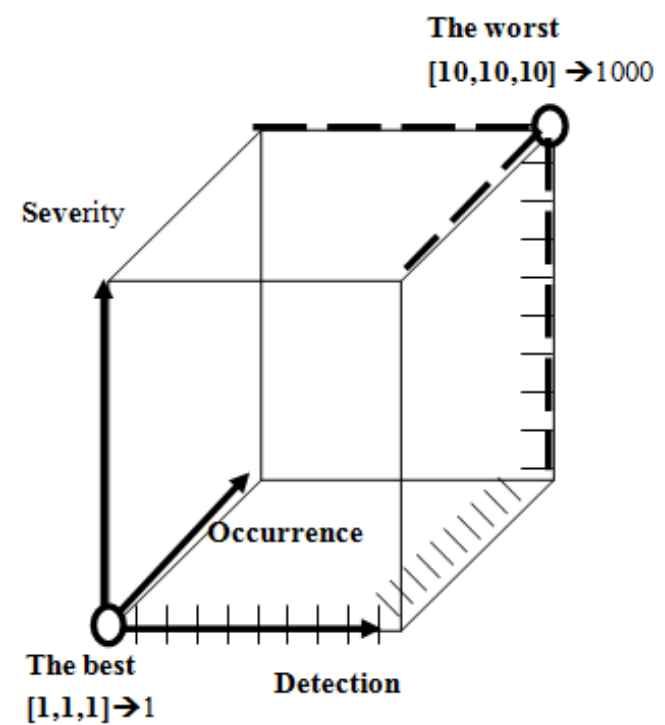

Figure 4-c. Cartesian representation of the FMEA scale [D, $\boldsymbol{O}, \boldsymbol{S}] \rightarrow R P N$, comparison of two design proposal versions $[1,1,1] \rightarrow 1 \&[10,10,10]$ $\rightarrow 1000$.

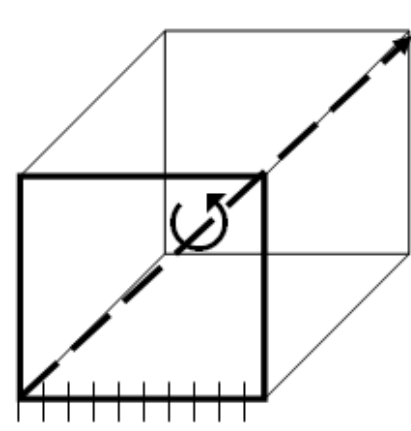

$[10,5,6] \rightarrow 300$

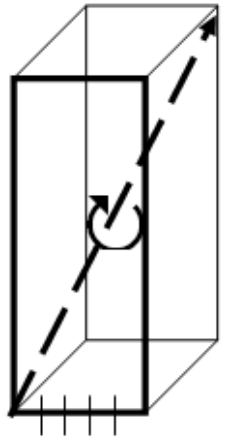

$[\mathbf{5}, \mathbf{3}, \mathbf{9}] \rightarrow 135$
Figure 4-d. Contraction and rotation of the Risk Priority Number as the design proposal shifts between two versions, based on vector representation.

"Fig. 4" shows four suggested techniques to represent the FMEA scale. The first is illustrated in "Fig. 4.a" as three linear histograms of the linear 10 -scale and one histogram of the RPN. The scale of RPN is not linear, and its possible numerical values can be statistically found. The second is depicted in "Fig. 4.b" as a polar representation of RPN, a proposed design being shown as a triangle. It is worth noting that the area of the illustrating triangle cannot be considered as a comparative measure. The third is given in "Fig. 4.c" as a box whose sides are the RPN factors. Each side has 10 units on the 10-scale of the three attributes. Thus an interesting result is that the version RPN is numerically the volume of the resulting box.

The fourth is demonstrated in "Fig. 4.d" as a the vector representation of RPN which has the form

$$
\mathrm{R}=\mathrm{X}_{\mathrm{i}}+\mathrm{Y}_{\mathrm{j}}+\mathrm{Z}_{\mathrm{k}}
$$

Or

$$
\mathrm{R}=\mathrm{D}_{\mathrm{i}}+\mathrm{O}_{\mathrm{j}}+\mathrm{S}_{\mathrm{k}}
$$

In order to analyze the successive development of a design proposal, we estimate the rate of change of RPN vector via finding the divergence as

$$
\nabla \cdot \mathrm{R}=(\partial / \partial \mathrm{x}) \mathrm{D}+(\partial / \partial \mathrm{y}) \mathrm{O}+(\partial / \partial \mathrm{z}) \mathrm{S}
$$

In addition, we estimate the rate of rotation of RPN vector, we find the curl

$$
\nabla \times R=\left[\begin{array}{lcc}
i & j & k \\
\partial / \partial x & \partial / \partial y & \partial / \partial z \\
D & O & S
\end{array}\right]
$$

\section{The Markov Formulation}

An entity (original, created, added or introduced) is supposed to be somehow useful for the remaining entities. For a closed system, creation reflects resources transfer or assets exchange among entities. In other words, a gained usefulness has a counterpart loss/ harm/ cost/ withdraw/ drain/ negative effect. This harm may affect one or more entities with various severities.

An entity is safe if its harmful rate/effect does not badly disturb the accepted Equilibrium State with its surrounding (the mutual survival with other components in the universe other entities accepts and afford the resulting loss/harm).

In this approach, an interesting concept is adopted. The concept is similar to the before-history circumstances when man started to accommodate his needs with his resources. Man uses his available resources to come up with a certain machine which enables him to satisfy his needs much easier. However, he notices that continuous operation of this machine drains his resources. He then tries to back up his machine with a parallel system or a correcting machine which compensates the losses of the original machine. We notice that this approach considers the man as the today $\mathrm{s}$ three partners; the designer, the manufacturer, and the customer. For instance, man invented the transportation means to make his traveling across vast areas much faster and easier. But cars have a lot of resource-draining features, starting from operation detrimental effects such as air pollution, oil consumption, and non-recyclable parts, and ending with the control of defects consequences via maintenance, repair, parts replacement, and accident insurance compensations. That is why, man established so many systems to subsidy the cars operations, such as fuel cells, roads pavement, traffic regulations, and accidents insurance and liability.

Man plans to transform his own assets (intellectual thoughts, physical features, wealth, properties, and time/age) along with his natural resources (animals, plants, land, air, water) to bring about new manufactured products. The creation process may be viewed as resources transformation/ conversion/ paraphrase/ exchange from a natural state to an artificial synthetic state.

The Markov formulation consists of the following steps;

- estimate the reward/ remunerate/ compensate/ trade-off 
$\mathrm{G}$ as reasons to create the intended manufactured product.

- estimate resources drained for creation; = design + manufacturing + protection $\mathrm{C}_{0}$ until before operation

- estimate resources drained towards filtering $\mathrm{C}_{1}$ (tuning to, screening, sorting) the defected items $=$ scraps + inspection cost

- add resources drained to continuously operate the manufactured produc $\mathrm{C}_{3}$.

- estimate resources drained to cover the consequences of passed intrinsic defects and induced defects as both grow up (maintenance, repair, replacement, compensation) $\mathrm{C}_{2}$.

$\mathrm{C}_{0}, \mathrm{C}_{1}$ before product birth, once and stop, manufacturer

$\mathrm{C}_{2}, \mathrm{C}_{3}$ perpetual expenditures, user operation

However, there are two reservations. First, both parties of the transformation are in a closed universe which implies that the gain cannot exceed the drain. Second, since man-planned transformation is constrained by a certain efficiency, the gain is not equal to the drain. Therefore, we should always expect that the gain is less than the drain. Thus,

$$
\mathrm{G}<\mathrm{C}_{0}+\mathrm{C}_{1}+\mathrm{C}_{2}+\mathrm{C}_{3}
$$

Assuming that the manufactured products and man will share the natural resources over a quite span of time with no circumstances change.

As an example, we will consider the three-member closed universe shown in "Fig. 5". The man, member B, has created two products, being A to perform a profitable or useful task and $\mathrm{C}$ to restore the defect growth consequences along with operation drains of product A. In car industry, the car is the useful product member A. Corrective and recycling systems $\mathrm{C}$ takes on various forms. In the car itself the product member $\mathrm{C}$ is the mufflers and cooling devices. In addition, cars tires, glass, metals are commonly recycled, whereas traffic regulations, road networks, and insurance policies reduce resources drain. For the given example, it is known in advance that available resources of 1000 units are shared by the three members. The man started with version 1 of the two products. In version 1, the product A needs 200 resources units, and the product $\mathrm{C}$ needs 300 resource units, and man retains the remaining part of 500 resource units. Since the man is not satisfied with version 1 , he will plan to optimize towards design version 2 with rearrangement of the same resources. Assuming that this process will indefinitely continue, we look for the steady state share of the man from the resources which will indicate whether it is sufficient and safe for the man survival.

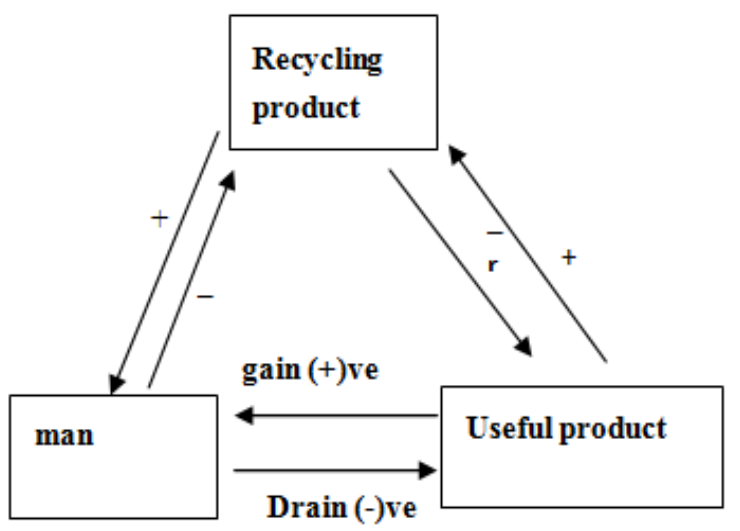

Figure 5. Compromised safety for man with two created manufactured products. Resources transfer reach an acceptable steady state based on Markov formulation.

Table 1 shows the original version, and the resources transfer toward an enhanced version 2. Table 2 shows how to build the transposed probability matrix. The importance of the probability matrix stems from the fact that the same result of version 2 could have been obtained from this matrix as follows [10 and 11].

Table 1. Resources transfer upon transition between two successive versions of a design proposal.

\begin{tabular}{lllllllll}
\hline \multirow{2}{*}{ Members } & version 1 & \multicolumn{2}{l}{ Gains from } & \multicolumn{2}{c}{ Losses to } & version 2 \\
\cline { 2 - 8 } & Original resources & A & B & C & A & B & C & Updated resources \\
\hline A & 200 & 0 & 35 & 25 & 0 & 20 & 20 & $200+(35+25)-(20+20)=220$ \\
B & 500 & 20 & 0 & 20 & 35 & 0 & 15 & $500+(20+20)-(35+15)=490$ \\
C & 300 & 20 & 15 & 0 & 25 & 20 & 0 & $300+(20+15)-(25+20)=290$ \\
\hline
\end{tabular}

Table 2. Building the transpose of the probability matrix $[P]^{t r}$

\begin{tabular}{llll}
\hline & to A & to B & to C \\
\hline from A & $160 / 200=0.800$ & $20 / 200=0.100$ & $20 / 200=0.100$ \\
from B & $35 / 500=0.070$ & $450 / 500=0.900$ & $15 / 500=0.030$ \\
from C & $25 / 300=0.083$ & $20 / 300=0.067$ & $255 / 300=0.85$ \\
\hline
\end{tabular}

$$
\begin{gathered}
{[\mathrm{P}]\left\{\mathrm{V}_{1}\right\}=\left\{\mathrm{V}_{2}\right\}} \\
{\left[\begin{array}{lll}
0.8 & 0.07 & 0.083 \\
0.1 & 0.90 & 0.067 \\
0.1 & 0.03 & 0.850
\end{array}\right]\left\{\begin{array}{l}
0.2 \\
0.5 \\
0.3
\end{array}\right\}=\left\{\begin{array}{l}
0.22 \\
0.49 \\
0.29
\end{array}\right\}}
\end{gathered}
$$$$
[\mathrm{P}]\left\{\mathrm{V}_{\mathrm{i}}\right\}=\left\{\mathrm{V}_{\mathrm{i}+1}\right\}
$$

Thus, for $\mathrm{i}=2$, we can get the shares of version 3 as And for $i=3$, we can get the shares of version 4 as

In general, we have 


$\left[\begin{array}{lll}0.8 & 0.07 & 0.083 \\ 0.1 & 0.90 & 0.067 \\ 0.1 & 0.03 & 0.850\end{array}\right]\left\{\begin{array}{l}0.22 \\ 0.49 \\ 0.29\end{array}\right\}=\left\{\begin{array}{l}0.234 \\ 0.483 \\ 0.283\end{array}\right\}$
$\left[\begin{array}{lll}0.8 & 0.07 & 0.083 \\ 0.1 & 0.90 & 0.067 \\ 0.1 & 0.03 & 0.850\end{array}\right]\left\{\begin{array}{l}0.234 \\ 0.483 \\ 0.283\end{array}\right\}=\left\{\begin{array}{l}0.245 \\ 0.477 \\ 0.278\end{array}\right\}$

The probability matrix expresses a system of linear equations in the form

$$
\left[\begin{array}{lll}
0.8 & 0.07 & 0.083 \\
0.1 & 0.90 & 0.067 \\
0.1 & 0.03 & 0.850
\end{array}\right]\left\{\begin{array}{l}
\mathrm{A} \\
\mathrm{B} \\
\mathrm{C}
\end{array}\right\}=\left\{\begin{array}{l}
\mathrm{A} \\
\mathrm{B} \\
\mathrm{C}
\end{array}\right\}
$$

Subject to the condition of

$$
\mathrm{A}+\mathrm{B}+\mathrm{C}=1
$$

Solving these equations, we then get a possible steady state of equilibrium with the following shares

$$
\left\{\begin{array}{l}
A \\
B \\
C
\end{array}\right\}=\left\{\begin{array}{l}
0.273 \\
0.454 \\
0.273
\end{array}\right\}
$$

\section{Discussion}

(1) Common aspects of the three methods shown are the data randomness and the optimization (compromising, minimizing) trend.

(2) Comparison of the available approaches shows some common grounds.

a- Industrial systems (plant/product) are manmade and man-operated, and then intrinsic and induced pitfalls/defects are inevitable. When the system is primitive, minor defects with insignificant consequences are expected.

b- Sophisticated systems are most likely to include a variety of defects with overwhelming losses. The system defects are the main concern of the quality studies. Direct or indirect losses, incurred by man and his natural resources, due to defects growth are the main concern of the safety studies. That is why safety researchers found their justification to follow the same well-established Quality Avenue as shown in"fig. 3".

c- At this point, we have two main safety formulas; namely the statistical process control SPC and the failure models and effects analysis FMEA. Both equations "(5) and (8)" are appropriate to define safety, to assess it, to control it, and to enhance it. The two formulas follow the inspection of $100 \%$ of the system items, include manufacturing randomness, refer to the tri-role of designer/ manufacturer/ user, and compromise the safety against the affordable cost. However, the SPC solely depends on data of measuring devices whereas the FMEA scale focuses on the human discretion.

d- The transfer and exchange of gain/loss or benefit/harm are the main trend followed in Markov analysis. In transient states, safety concern may exceed the expenditures or vice versa. However, when man reaches a balanced state with his industrial system, and also the another entities of environmental system as perspective ecological balancing for environmental closed system (ECS).

(3) we then also face a kind of compromise between the safety and affordable cost. The main advantage of Markov is the inclusion of the primary gain behind creation reasons of the direct and indirect detrimental effects of industrial system on environmental system.

\section{Conclusion}

(1) We notice that the quality approach has not yet established a well-defined code to formulate the safety area of the product quality.

(2) Nevertheless, the quality/defects relationship is similar to the safety/defects consequences or loss relationship. This similarity makes it legitimate to reformulate the quality charts as product safety charts where quality produces safety, and makes for quality .

(3) The risk priority number estimated by the FMEA technique has two drawbacks. First, estimation of the constituting factors, especially the detection and severity, depends primarily on the discretion of the designer, and thereby they fall in a wide margin for a given design version. Second, there is no clear end to stop the optimization further processing. This makes the product design crew ignores where its proposed design stands with respect to an optimum version. In the present study, we put forth four methods to geometrically express the RPN. Each method provides an extendable mathematical basis toward the optimization sought.

(4) We rank the Markov formulation as the promising approach to efficiently handle the product safety in terms of the resources gain and drain. However, based on the irreversibility principles governing the manufactured products, imperfect resources transfer still calls for further refinement of the formulation before a full and dependable applicability is realized.

(5) Thorough comparison of the three methods yields some guiding means. For instance, comparing the FMEA technique with the quality approach results in a compromised RPN as recommended safety level, involving accepted defects is given by $\mathrm{S}=(\mathrm{b} / \mathrm{a})^{0.5}$ and a minimum resources loss cost as $2(\mathrm{a} \mathrm{b})^{0.5}$ where:

$\mathrm{a}=$ constant for preventive safety at design and manufacturing stage.

$\mathrm{b}=$ constant for liability safety for maintenance, repair, and replacement. In addition, insurance compensations have to cover losses in lives and damages in properties.

(6) Also when comparing the FMEA technique with the Markov formulation we observe that the severity factor, and acceptable state nearly corresponds to the function of the 
recycling product (c) with severity state or operation drains or loses incurred by the user.

(7) The comprehensive resource-loss trend helps product designers must meet a wide range of customer requirements and operational regulations as perspective environmental closed system (ECS).

\section{References}

[1] X.cuny and M. Lejeune, Statistical modeling and risk assessment, Safety Science, Vol. 41, Issue 1, Feb. 2003, PP. $29-51$.

[2] J. L. Rouvroye and E. G. Van dan Bliek, Comparing safety analysis techniques, Reliability Engineering \& System Safety, Vol. 75, 2002, PP. 289-294.

[3] Hossam A. Gabbar, kazuhiko Suzuki, and Yukiyasu shimada, Design of plant safety model in plant enterprise engineering environment, Reliability Engineering \& System Safety, Vol. 73, 2001, PP. 35-47.

[4] S. J. Cox, and A. J. T. Cheyne, Assessing safety culture in offshore environments, Safety Science, Vol. 34, 2000, PP. 111-129.

[5] Leo Beltracchi, Plant and safety system model, Reliability Engineering \& System Safety, Vol. 64, 1999, PP. 317-324.
[6] Birgitte Rasmussen, and Kurt E. Petersen, Plant functional modeling as a basis for assessing the impact of management on plant safety, Reliability Engineering \& System Safety, Vol. 64, 1999, PP. 201-207.

[7] Jon G. Anderson, Jeffrey D.E. Jeffries, Todd P. Mairs, and Frank J. Rahn, Optimized work control process to improve safety and reliability in a riskbased and deregulated environment, Reliability Engineering \& System Safety, Vol. 63, 1999, PP. 225-229.

[8] [8] K. Nytrö, P. ö. Saksvik, and H. Torvatn, Organizational prerequisites for the implementation of systematic health, environment and safety work in enterprises, Safety Science, Vol. 30, 1998, PP. 297-307.

[9] C.J. Price and N.S. Taylor, Automated multiple failure FMEA, Reliability Engineering \& system safety Vol. 76, Issue 1, April 2002, pp 1-10.

[10] J.L.Rouvroye, E.G.Van den Bliek, Comparing Safety Analysis Techniques, Reliability Engineering and System Safety V75, 2002, pp. 289 - 294.

[11] Tieling Zhang, Wei Long and Yoshinobu Sato, Availability of systems with self-diagnostic components - applying Markov model to IEC 61508-6, Reliability Engineering \& System Safety, Volume 80, Issue 2, May 2003, pp.133-141. 